\title{
"EU TERIA FICADO EM PRISÃO PERPÉTUA COM ELA": AFETO E AGÊNCIA NA TRAVESSIA POR UMA PENITENCIÁRIA FEMININA NO MARROCOS
}

\section{"I WOULD HAVE SPENT MY LIFE IN PRISON WITH HER": AFFECT AND AGENCY IN PASSAGES THROUGH A FEMALE PRISON IN MOROCCO}

\section{Nathalia Ferreira Gonçales}

nathalia.goncales@hotmail.com

Doutoranda pelo Programa de Pós-graduação em Antropologia Social do Museu Nacional da Universidade Federal do Rio de Janeiro. Pesquisadora vinculada ao Núcleo de Estudos em Corpos, Gêneros e Sexualidades (NuSex/ Museu Nacional).

ORCID: https://orcid.org/0000-0002-6934-849X

\section{Montserrat Valle Prada}

mmonxi@gmail.com

Possui mestrado pelo Programa de Pós-graduação em Saúde Coletiva no Instituto de Medicina Social da Universidade do Estado do Rio de Janeiro. Pesquisadora vinculada ao Núcleo de Estudos em Corpos, Gêneros e Sexualidades (NuSex/Museu Nacional).

ORCID: https://orcid.org/0000-0002-4048-6821

\section{RESUMO}

A partir da história de Rita, detida na fronteira da cidade espanhola de Ceuta com a província marroquina de Tetuão e, posteriormente, encarcerada no Centro Penitenciário feminino de Tetuão, a prisão referida é elaborada como uma passagem da fronteira que vai além de uma localização limítrofe entre Espanha e Marrocos. No plano do ordinário, diz respeito a um território no qual se produzem redes de solidariedade, diferenciações, fraturas e porosidades. A travessia de Rita cria o cenário onde são cartografadas algumas relações que perpassam circulações transnacionais e significados dos muros entre as pessoas que habitam as bordas hispano-marroquinas. Na prisão, Rita conhece Naima. Se o vínculo entre elas funda uma agência a partir da qual podem se recompor da cruenta cotidianidade prisional, o que chamamos de travessia pelo cárcere emerge como determinante na composição da fantasia de um futuro a dois, agindo enquanto motor instigador de possíveis devires na construção da fronteira que protagoniza esta escrita.

Palavras-chave: fronteira; prisão; Espanha; Marrocos.

\section{ABSTRACT}

This text reflects on the story of Rita, who was detained in Ceuta, a Spanish city bordering the Moroccan province of Tétuouan. Later, Rita was imprisoned in Tétuouan's Central Penitentiary for Women, and the text explores her 
imprisonment as a passage along a border that is not simply the physical frontier between Spain and Morocco: in ordinary life, this border applies to a territory in which networks of solidarity are produced, together with differentiations, fractures, and porosities. Rita's passage creates a setting in which certain relationships that run through transatlantic circulations can be mapped out, together with the meanings of the walls erected between people who inhabit the edges of Spanish-Moroccan divides. While imprisoned, Rita met Naima. If the link between these two women established an agency through which they were able to recover from the bloody everyday reality of prison, their passage through the prison system emerged as a determinant factor in composing the fantasy of a future together. In turn, this fantasy instigated possible becomings in constructing the borderlands that are the focal point of this work.

Keywords: border; prison; Spain; Morocco.

\section{UMA PONTE ENTRE A FRONTEIRA E O CÁRCERE}

A fronteira entre Ceuta, Espanha, e Tetuão, Marrocos, se consolida por 6,3 quilômetros de cercas de arame equipadas com dispositivos de vigilância no seu perímetro. Neste artigo, buscamos esmiuçar tal demarcação como uma ponte tomada por múltiplas diferenças reveladas na experiência de encarceramento de Rita no Centro Penitenciário feminino de Tetuão, Marrocos, província adjacente à cidade espanhola de Ceuta. Esta pesquisa é resultado de uma série de entrevistas reunidas durante nossa experiência de campo na Espanha, entre dezembro de 2016 e fevereiro de 2017. Embora não consista em um eixo analítico a ser aprofundado nos parágrafos seguintes, parece-nos importante registrar que Rita é tia paterna de uma das autoras que assinam o texto. Desta maneira, o arranjo narrativo confere à escrita etnográfica modulações que transitam por memórias e temporalidades assíncronas.

Rita é espanhola, filha caçula e única mulher entre cinco irmãos homens, criada em Torre-romeu, um bairro periférico da pequena cidade de Sabadell, localizada na província de Barcelona. Torre-romeu é um complexo de prédios e casas povoado inicialmente pela onda migratória procedente do sul da Espanha durante o período pós-guerra civil, no transcurso do século XX - como é o caso de seus pais e irmãos, nascidos nos arredores da província andaluza de Granada e conduzidos a um processo de deslocamento até habitar dito bairro. Atualmente, com uma população de 6 mil moradores, Torre-romeu constitui uma das zonas da comunidade autônoma da Catalunha com maior porcentagem de população de etnia cigana e migrantes de origem marroquina e subsaariana. Dois dias após ser detida na fronteira hispano-marroquina por "tráfico transnacional de drogas" ${ }^{1}$, em 25 de fevereiro de 2012, Rita foi encarcerada no Centro Penitenciário feminino da cidade de Tetuão com então 39 anos de idade. Inicialmente condenada a quinze meses de cárcere e uma multa alfandegária de 165.000,00 euros, dita sanção se 
prolongou até vinte e sete meses de encarceramento pela impossibilidade de liquidar a penalização econômica.

Fazendo um paralelo entre a fronteira e o universo prisional (DAVIS; DENT, 2003), o cárcere pode ser pensado como uma zona limítrofe pela própria partição dos muros ao determinar o dentro e o fora. Resultaria impossível conceber o dispositivo carcerário do Centro Penitenciário de Tetuão de forma isolada ao complexo jurídico-militar da fronteira hispano-marroquina, e vice-versa. Pensar a prisão de Tetuão como um espaço transfronteiriço permite nos debruçarmos sobre os limites nacionais dos Estados, de modo a identificar formas organizadas e atualizadas onde se desdobram, além dos domínios de poder entranhados nas micropolíticas cotidianas - marcados por hierarquias raciais, de gênero, classe, religião e sexualidade -, outras vivências atravessadas pela unidade penitenciária, como afetos, agenciamentos entre sujeitos e gestos de solidariedade balizados no dentro/fora da instituição. Se a fronteira hispano-marroquina é a abordagem deste artigo, a prisão de Tetuão constitui a passagem narrativa na qual o relato de Rita se contextualiza.

\section{O INÍCIO: TROCAS DE AFETO NA PRISÃO}

Rita e Naima habitavam a mesma cela no Centro Penitenciário feminino. Naima era uma mulher de origem marroquina, nascida e criada junto a sua família em uma vila situada na zona rural da província de Tetuão. Seu pai, mãe, sete irmãos, cunhados e sobrinhos moravam uns ao lado dos outros em pequenas casas construídas com tábuas de madeira e pranchas de metal. Na parte exterior do local, havia um forno à lenha onde assavam pães, que eram posteriormente enrolados em panos e guardados em um lugar seco para que permanecessem macios por mais tempo. No vilarejo, Naima trabalhava no campo colhendo camomila, azeitonas e mel. Lá, aprendeu a cozinhar e elaborar queijo. A narrativa de Rita nos introduz diretamente à trajetória de vida de sua companheira. Sabemos que Naima foi presa por uma armadilha jurídica conspirada na acusação de um policial sexualmente rejeitado por ela. $\mathrm{O}$ agente incriminou Naima por porte de drogas ilegais, plantando provas falsas no relatório da denúncia que ocasionou em sua detenção e encarceramento. Na prisão, Naima tentou reverter tal inculpação recorrendo a um advogado, mas o apelo jurídico resultou ineficiente e tardio.

Durante o cumprimento da pena, as duas construíram uma relação de confiança, apoio mútuo e afeto. Cozinhavam e comiam juntas todos os dias. Rita conta que adorava o jeito de Naima na hora das refeições, por nunca se servir antes que todas as companheiras estivessem prontas para comer. Após o almoço, durante cada tarde, sentavam-se na cama e passavam as horas juntas conversando, rindo e estudando espanhol. 
Nesta experiência costurada entre comedimentos e paixões, Rita não esquece os olhares das funcionárias e outras companheiras de cela quando se aproximavam:

Eu teria ficado lá em prisão perpétua com ela, toda a vida. Os dias passavam voando quando estava com ela. Olha, Marrocos me colocou lá, mas encontrei uma pessoa muito bonita que, por outro lado, fez a prisão e os dias passarem mais rápido, sabe? Estávamos bem, embora não nos deixassem fazer nada.

Rita encontrou uma forma de aliviar o sofrimento produzido pelo encarceramento. A proximidade e carinho que sentia por Naima aceleravam o transcurso temporal da pena. Se no princípio era só uma companheira de cela a mais, a medida que passavam os dias, Naima foi se tornando a pessoa mais íntima no seu cotidiano. Não tardou em aflorarem desejos cujas manifestações corporais foram constantemente desautorizadas pela política de vigilância e gestão da vida na penitenciária. As outras mulheres presas também contribuíam para o controle das expressões afetivo-sexuais entre Rita e Naima, e os murmúrios que ecoavam pelos corredores da cadeia restringiam qualquer tipo de afago.

Na literatura sobre emoções e prisão, Sabrina Rosa Paz (2009) realiza um estudo sobre experiências de namoro e exercício da sexualidade de mulheres encarceradas no Presídio Estadual de Rio Grande, instituição que comporta homens e mulheres em seu interior. A autora contempla como as práticas e valores afetivos são redimensionados na passagem pelo presídio, não só nos vínculos fraturados, intensamente analisados pela obra de Natália Corazza Padovani (2015), e nas rupturas que produzem as dinâmicas carcerárias, senão também nas continuidades engendradas pela manutenção e conquista de "parcerias afetivas para 'puxar junto' a cadeia" (PAZ, 2009, p. 86), através de cartas, trocas de objetos e gestos desde as janelas e pátios. Esses elos afetivos, intermediados por mecanismos de regulação da vida e das relações, inseridos nos processos de Estado das prisões femininas são vivenciados pelas detentas no interior de tramas e negociações com os agentes envolvidos. No caso de Rita e Naima, seu relacionamento ganha conotações transnacionais, evidenciando passagens assimétricas que marcam as tensões da relação amorosa estabelecida dentro da instituição prisional.

\section{A CONSTRUÇÃO DAS FRONTEIRAS TRANSNACIONAIS: O IMPERATIVO RACIAL E RELIGIOSO}

A parte exterior do prédio dispunha de um pequeno pátio quadrado com um varal onde as mulheres estendiam suas roupas para secar. Algumas delas gostavam de tomar um ar fresco, outras aguardavam até a finalização da secagem para evitar o furto das peças. O horário de saída para o pátio era das 9 horas até as 12 horas, na parte da manhã, 
e das 14 horas até as 16 horas, na parte da tarde, totalizando cinco horas diárias. $\mathrm{O}$ acontecimento que será relatado ocorreu em um dia frio de primavera. As nuvens cinzentas anunciavam a chuva que logo viria, o relógio marcava 14:30. Rita e Naima eram as únicas pessoas a ocupar o pátio da penitenciária. Uma funcionária passou por lá e, ao vê-las juntas, ordenou-lhes que entrassem no prédio. Incomodada pela imposição, Rita assinalou que o horário de saída para o pátio era permitido pelas regras da instituição. A funcionária insistiu na diretriz, opondo-se à estância das duas sozinhas. Após algum murmúrio abafado, Rita e Naima subiram as escadas que davam acesso à parte interior da penitenciária. Rita conta:

Já tínhamos criado fama. Nós estávamos juntas de palavra, mas não de fato, porque não nos deixavam fazer nada. Lá não pode. Em parte, também é um tema religioso. Não é bem visto que Naima, sendo muçulmana, esteja comigo, que sou vista como cristã. Nos diziam: - o que acontece é que uma é serrania, como se referiam às católicas, e a outra muçulmana. Porque lá têm outras garotas marroquinas que estão juntas e não fazem tanto ruído como nós, deve ser porque são muçulmanas. Temos duas coisas contra nós: por um lado, são mal vistas as relações entre duas mulheres e, por outro lado, a religião.

O vínculo afetivo entre Rita e Naima vai sendo produzido no meio das tramas prisionais. Nessas urdiduras, o controle da sexualidade e da intimidade das presas era comum nas práticas institucionais da penitenciária e nas funções das funcionárias, o que tornava a relação de intimidade entre as duas um fragmento fictício quase secreto. Além disso, as relações que se davam na cadeia eram policiadas pelas próprias presas. No rigor disciplinar que distinguia as condutas consideradas adequadas daquelas inapropriadas, a categoria serrania emerge para designar um atributo cristão à pessoa assinalada. Ainda que nunca tivesse participado dos atos sacramentais da igreja católica, Rita era chamada de serrania pelas outras presas e funcionárias marroquinas. Para ela, essa identificação era um dos principais motivos que dificultava seu relacionamento afetivo com Naima, praticante da religião islâmica. Através das categorias muçulmana e serrania, a religião - conjugada à nacionalidade - funcionava como um eixo diferencial entre as mulheres presas marroquinas e europeias, respectivamente.

$\mathrm{Na}$ sua visita à Prisão Estadual Calipatria, na Califórnia, Angela Davis e Gina Dent (2003) percebem uma organização das celas baseada na separação racial, distribuição que impossibilita a coabitação entre presas brancas, negras e chicanas. As autoras apontam para o histórico de violências que a segregação racial engendra nas prisões femininas. Deste modo, as políticas de demarcação étnico-racial se encontrariam diretamente vinculadas às possibilidades de afeto e exercício da sexualidade. Coexistindo no dentro e fora do cotidiano carcerário, o cruzamento entre raça, etnicidade e sexualidade envolve regras e técnicas 
de regulação dos corpos. De forma similar, no Centro Penitenciário feminino de Tetuão, as dinâmicas de diferenciação racial entalhadas sob marcações de nacionalidade e religião têm um impacto significativo na configuração de vínculos e parcerias. Considerando a religião enquanto componente fundamental nos processos de racialização dos sujeitos presos, cabe destacar que as desigualdades de gênero, classe e sexualidade são articuladas na configuração das matrizes de violência que recaem sobre os corpos das mulheres encarceradas em Tetuão.

A percepção de Rita a respeito dos domínios normativos reguladores dos contatos afetivo-sexuais entre as detentas traz à tona, em primeira instância, o impacto do regime heterossexual enquanto unidade fictícia capaz de agrupar certas condutas e estratificações do corpo em função de uma ordem moral do desejo. Na narrativa de Rita, as relações sexuais entre mulheres na penitenciária resultavam menos "ruidosas" se acontecessem entre duas mulheres marroquinas do que se, distintamente, ocorressem entre uma mulher marroquina e outra não-marroquina. A interrupção das trocas de carinho com Naima era modulada por discursos da diferença que, de forma paralela, acionavam representações nacionais e religiosas inseridas em processos de racialização extremamente assimétricos.

A gestão da pena se articula a diversas tecnologias disciplinares (FOUCAULT, 2012). O encarceramento fragmentado espacialmente em celas diferenciadas e espaços territorializados classifica as detentas no interior de uma malha de relações de poder capaz de gerar hierarquias entre os diferentes agentes que transitam pelo dentro/fora da penitenciária. As vigilâncias constantes por parte das funcionárias, os estritos horários de fechamento das celas, o racionamento de água quente, a escassez alimentar e a privação de relações afetivo-sexuais são alguns dos dispositivos de regulação dos corpos no cenário carcerário. A fixação de uma economia do tempo e de limites espaciais configura a arquitetura da penitenciária e produz sistemas de diferenciação entre as presas.

A história de Rita permite analisar algumas relações estabelecidas entre os diferentes agentes que circulam pela penitenciária feminina de Tetuão, principalmente entre as mulheres encarceradas e as funcionárias da instituição. Tais interações configuram uma teia de vínculos que circundam o dentro e o fora da prisão, na qual a fronteira carcerária vai adquirindo porosidades num interior/exterior nem sempre reconhecível. Se bem o dentro e fora da penitenciária se mostram rígidos através dos seus paredões e janelas opacas, a circulação de afetos e "substâncias compartilhadas", para usar os termos de Janet Carsten (2004), indica as linhas de fuga pelas quais se movimentam intensidades e fluxos de afeto nos enredos da vida cotidiana.

Os dolorosos processos de encarceramento vão sendo compartilhados dia após dia por meio de múltiplas trocas. Fazendo referência à teoria de Carsten (2004) sobre o "espessamento" e a "diluição" do parentesco 
através das "substâncias" entrelaçadas nos intercâmbios intrínsecos à penitenciária, Padovani (2015) já apontou que tais "substâncias" se referem ora a objetos concretos - como comida, dinheiro, sabão ou lugar de moradia -, ora a outras substâncias que produzem materialidade - como afetos, ajuda mútua, memórias, emoções e pensamentos. A presença e a troca de "substâncias" entram em jogo no convívio de sujeitos enredados nas travessias penais, modificando as vivências relacionais e subjetivas da prisão.

Neste sentido, Natália C. Padovani (2015) alerta como as redes afetivas vivenciadas a partir da experiência prisional intervêm nas trajetórias dos sujeitos no dentro/fora do cárcere e anunciam "espaços privilegiados de agência e regulação" ou, ainda, "formas de vivenciar liberdades a partir da instituição prisional” (PADOVANI, 2015, p. 35). Assim, as trocas afetivas operam cotidianamente como suportes de vida e, diversas vezes, extravasam os laços consanguíneos do que se entende como família. Redes de afeto, ajuda e solidariedade articuladas na experiência carcerária enredam vidas profusas, a despeito dos elos entre o cumprimento da pena e a projeção de liberdade. Nesse registro, a prisão é produtora de políticas de amizade e cuidado diante do sofrimento, da solidão e das saudades vivenciadas - emoções que podem se estender mesmo após o cumprimento da pena.

Rita comenta que estar perto de Naima fazia com que permanecesse firme apesar das adversidades que surgiam em sua travessia pela instituição prisional. De fato, o envolvimento entre elas revela uma força capaz de minar o caráter individualizante da pena que, segundo Foucault (2012), não pretende outra coisa que a regulação minuciosa de associações, cumplicidades e solidariedade entre as presas. A proximidade entre Rita e Naima conecta suas vidas por meio de histórias contadas entre elas. No interior dos processos de privações, o reconhecimento desse afeto se torna uma estratégia de autogestão na travessia pela prisão, possibilitando a transmutação de suas experiências carcerárias em formatos inteligíveis de vida. Se as práticas de desumanização e as técnicas de controle dos afetos entre as mulheres em cumprimento de pena são preceitos que tangenciam os operativos jurídico-disciplinares da trama carcerária, observamos que a rede de cuidado estabelecida entre Rita e Naima contém traços profundamente comprometidos com a ressignificação de seus trânsitos por esse cenário.

A vivência de Rita pelo subúrbio espanhol e pelo cárcere de Tetuão mostra como as violências estatais e sociais se derramam sobre seu corpo. Rita circula por um jogo identitário vacilante, invocando diferentes possibilidades de se colocar no mundo. Em algumas lembranças sobre sua passagem pela cadeia, manifesta certa proximidade à concepção ocidental do que entende por "liberdade, direitos sexuais e de gênero". No cárcere de Tetuão, a religião muçulmana é percebida por ela como um instrumento de vigilância íntimo de desejos, prazeres e proximidade 
entre o seu corpo e o corpo de Naima. Assim, a identificação de Rita com o modelo cultural de modernidade europeu revigora fantasias nacionalistas através de projetos políticos baseados na defesa das minorias sexuais e de gênero no Estado espanhol ${ }^{2}$. Porém, nos parece interessante apontar que Rita narrou diversos episódios de violência e silenciamento a respeito de suas relações afetivo-sexuais com outras mulheres em sua vida pregressa no subúrbio espanhol de Torre-Romeu.

A maioria das mulheres que habitava a penitenciária de Tetuão era de origem marroquina. Um pequeno número de mulheres, como Rita, provinha de Estados europeus, tais quais Espanha, Portugal e Itália. A nacionalidade se apresenta como um relevante marcador da diferença que, na interseção com outros processos de territorialização subjetivos e existenciais, arma uma rede de relações entre os agentes do dentro/ fora da prisão. O fato de ser espanhola despertava em Rita a segurança de que, caso não se envolvesse em problemas, um dia retornaria para o seu bairro periférico de Torre-romeu, posicionando-a em um lugar de conforto em relação às presas originárias do Marrocos. Em seu relato, é remarcada a distinção entre as condições das penitenciárias espanholas, segundo ela, equipadas com academias e bibliotecas e, no oposto, a carência estrutural da penitenciária feminina de Tetuão. Ademais, Rita percebia a situação de precariedade da instituição enquanto uma caraterística geral do Marrocos, como se o país inteiro fosse um aprisionamento desprovido do que ela entende por "liberdade".

Através dos movimentos de subjetivação de Rita, gostaríamos de remarcar a impossibilidade de separar fronteiras e trânsitos (BUMACHAR, 2016). As distâncias e proximidades são tecidas por meio das configurações relacionais entre Rita e os outros, entre estar dentro e fora desses intermezzos de caráter provisório, contraditório e ambíguo. Ser espanhola na penitenciária de Tetuão embaralha categorias de diferenciação, articulando noções de nacionalidade, raça, gênero e classe, que são negociadas e ressignificadas constantemente em função das possibilidades, agências e interesses. Dito de outra forma, longe de ser um princípio de unidade cultural interna, a nacionalidade se perfaz na confluência de outros eixos de diferenciação (BRAH, 2011) que, ao se imbricarem entre eles, moldam as relações sociais, a identidade e a própria experiência prisional. A materialidade dos limites prisionais e transnacionais é modulada em função das (inter)ações dos agentes com as políticas de gestão envolvidas nessa trama.

Para Rita, voltar para casa significava voltar para Espanha. Isso era uma das marcas cardinais que a diferenciava das outras companheiras de penitenciária e dava-lhe forças para ignorar os constantes insultos e brigas. O passaporte espanhol e seu lugar de origem a colocavam em uma posição onde existia um futuro ao qual aspirar cada noite quando, às $23 \mathrm{~h}$ em ponto, se apagavam as luzes da penitenciária. $\mathrm{O}$ futuro de voltar. O desejo de retornar para Espanha - território que, para Rita, 
constituía um lugar de conforto diante da situação na qual se encontrava - apaziguava a raiva que sentia em meio ao tumulto das brigas diárias. Assim, Rita criou seus mecanismos e condutas, aprendendo a ignorar os insultos dirigidos a ela como forma de agenciar seu bem-estar durante a travessia. Tais pensamentos, baseados na reafirmação de diferenças e assimetrias de pertencimento, possuíam o peso histórico de escalas de colonialidade implícitas a cada movimento de territorialização. Para alcançar uma suposta legibilidade "civilizada" frente à infração da lei, Rita acionava narrativas que a vinculam a uma "boa cidadã espanhola". Para ela, evitar brigas dentro da penitenciária a tornaria mais respeitável aos olhos dos agentes de governo, neste caso, frente às funcionárias.

$\mathrm{O}$ processo de diferenciação de Rita gravita em um vaivém, ora embranquecendo sua passagem pela cadeia na articulação dos privilégios derivados da sua cor de pele e nacionalidade, ora precarizando sua vida nos episódios de violência institucional ocorridos durante a sua travessia. Os cenários de fronteira entre Marrocos e Espanha se deslocam da linha divisória entre dois Estados-nações para serem incorporados nos intervalos da cotidianidade, em um contínuo de porções de vida que vai do bairro periférico de Torre-romeu até os mais profundos atravessamentos no corpo e nas relações de Rita na penitenciária. A emergência desse repertório de localizações diversas e flutuantes, mais ou menos estáveis e, às vezes, contraditórias, constitui a trajetória de vida da personagem; a ficção narrativa da sua experiência pelo contexto carcerário se conecta com múltiplos exteriores que complexificam a tarefa de realizar uma leitura sobre a fronteira. Precisamente, a confluência de forças subjetivas cria dobras e territórios submersos, oferecendo uma cartografia da travessia de Rita, que é impregnada por estratégias de produção de vida dentro e fora da penitenciária.

\section{A SAIIDA DO CÁRCERE}

Na manhã do dia 26 de maio de 2014, uma funcionária ordena que Rita se prepare para ser encaminhada pela polícia marroquina até a delegacia de Tetuão, órgão onde efetuará o procedimento administrativo de saída do cárcere. Rita havia cumprido sua sentença, totalizando vinte e sete meses de encarceramento. A despedida das companheiras e de algumas funcionárias sedimenta uma história tramada nas relações que foram surgindo durante a travessia pelo contexto prisional e fronteiriço do Centro Penitenciário. O momento da partida é vivido com tristeza, especialmente porque Naima permanecerá lá dentro. Rita cruza o portão de ferro que conecta ao exterior dos muros vestindo uma calça moletom e uma blusa de algodão. Não porta nenhuma mala consigo, já que todos os bens dos quais dispunha - roupas, sapatilhas, lençóis, produtos de higiene, comida e a televisão - foram repassados para Naima que, enquanto chora, escuta as promessas de Rita cada vez mais distantes: 
"meu coração fica aqui com você, nunca vou te esquecer, esperarei a vida inteira para voltar a estar junto contigo".

A luz do sol cega a vista de Rita. Com os olhos inchados, enxerga borrado o prédio da penitenciária desde o interior do carro oficial da polícia. Durante o trajeto até a delegacia, Rita jura para si mesma que todo esse dano será vingado, toda essa desgraça será reparada. $\mathrm{O}$ preenchimento dos documentos nos quais fica decretada a expulsão legal de Rita por dois anos do território marroquino se realiza com rapidez. À continuação, uma escolta a encaminha até a fronteira hispano-marroquina de Ceuta com Tetuão, justamente onde vinte e sete meses atrás havia sido detida por um operativo de registro fronteiriço e enquadrada no delito de tráfico transnacional de drogas. No lado espanhol da fronteira, Pablo, seu irmão mais novo, espera para levála até sua casa. O reencontro é impactante, Rita está diferente. Havia emagrecido muito, sua cabeça encontrava-se raspada, seus olhos estavam praticamente escondidos atrás das pálpebras inchadas e roxas e, além disso, a perda de sete dentes da mandíbula superior imprimia em seu rosto uma aparência prejudicada pela falta de cuidados. Rita entra no carro de Pablo e percorrem juntos o trajeto de 15 horas de estrada até o bairro periférico de Torre-romeu, Espanha.

Voltar à casa resultou estranho para Rita. Recorda estar vivendo em uma realidade distante pelo fato de poder se sentar no vaso, dispor de talheres, copos, descansar em uma cadeira, conservar os alimentos na geladeira - ao invés de guardá-los embaixo da cama, como fazia na prisão -, e, sobretudo, acudir ao médico para sanar sua saúde. A adaptação à nova vida lhe pareceu dificultosa. Usando as palavras de Padovani (2015), retornar para casa nem sempre implica reconhecê-la como tal. $\mathrm{O}$ apartamento vazio aumentava o sentimento de solidão acionado pela falta de Naima. Ao sair pelas ruas de Torre-romeu e cruzar com vizinhos e conhecidos, Rita sentia a necessidade de se resguardar em um lugar fechado. O processo de encarceramento deixou uma experiência de isolamento imiscuída em seu corpo, uma vivência que se estendeu para além da temporalidade da pena "privativa de liberdade".

\section{O SONHO}

Durante a estadia no cárcere, era comum que as companheiras raspassem a cabeça entre elas com tesouras emprestadas pelas funcionárias para evitar a infestação de piolhos. Três anos após a saída da penitenciária, os cachos desgrenhados de Rita já cresceram. Agora, sentada na cozinha do apartamento em que mora na Espanha, lembra com lucidez cada momento que viveu dentro dos muros de concreto. Sua memória evoca uma descrição detalhada de si, das companheiras e do entorno. "Nos vinte e sete meses que estive presa, não vi nenhuma cadeira, nenhuma mesa, nenhum banco para sentar. Fazíamos tudo no 
chão. Do que mais sentia falta era do silêncio, era como estar o tempo todo dentro de um bar. E isso me fazia muito mal", diz. Tal combinação de escassez e excesso, característica da penitenciária, percorre as nervuras de seu corpo enquanto ela divide conosco algumas histórias. A falta de produtos de higiene e vestimentas tinge suas lembranças sobre as companheiras que dispunham de um único pijama ou que rasgavam roupas em pedaços para usá-las como absorventes. O peso desses dias passados faz ponte com outros movimentos de afeto e solidariedade no dentro/fora da penitenciária. No fim das contas, sua passagem pela fronteira hispano-marroquina e o posterior encarceramento podem ser elaborados como uma experiência coletiva que vincula tantas outras trajetórias de vida.

"Eu não sou a mesma, eu mudei muito. Na prisão do Marrocos, entendi o que é a necessidade e isso mudou minha vida", pontua. Como já comentaram Padovani (2015), Mallart (2017) e Paz (2009), as experiências prisionais ressignificam os percursos da vida. As violências, abusos de poder, redes de solidariedade e elos afetivos do cotidiano carcerário penetraram o corpo de Rita. A cada dia, ela sonha com o momento em que, caminhando pela rua, reencontrará Naima, seu amor, e poderá abraçá-la sem os olhares vigilantes das funcionárias e outras presas. O vínculo de afeto travado entre as duas dentro da penitenciária inaugurou projetos de deslocamento motivados pela vontade de se aproximarem. No decurso das longas conversas telefônicas que elas mantêm diariamente, planejam estratégias para percorrer a distância que separa Marrocos da Península Ibérica, correspondente a quarenta minutos em barco. Por um lado, Rita tem medo de cruzar a fronteira hispano-marroquina e ser incriminada sem cometer nenhuma infração legal, devido aos antecedentes penais e às explanações midiáticas que carrega consigo. Por outro lado, os requisitos burocrático-legais que o Estado espanhol exige para o ingresso de sujeitos marroquinos em território europeu são dificilmente alcançáveis por Naima, especialmente no que se refere ao critério econômico.

No entanto, as duas vislumbram uma saída possível, uma aproximação urgente. Decidem se encontrar na cidade de Ceuta - zona de mobilidade fronteiriça que, ainda que pertença à nação espanhola, não faz parte do território europeu de livre circulação determinado pelo Acordo de Schengen ${ }^{3}$. Essa conjuntura cria uma condição especial para a população marroquina da zona de Tetuão, que consiste na permissividade do acesso legal à cidade de Ceuta sem exigência de visto, apesar de algumas restrições de horários, e proibição do trânsito de tais sujeitos para o resto do Estado espanhol e da Europa. Entre o fluxo de pessoas, mercadorias e outras substâncias que permeiam diariamente a fronteira hispano-marroquina de Ceuta-Tetuão, a cidade limítrofe de Ceuta condiciona um espaço limbo para que Rita e Naima finalmente possam se reencontrar: 
Quando nos encontramos em Ceuta, não acreditávamos que ninguém estivesse nos vigiando e dizendo que não podíamos estar juntas. Custava até que a gente se olhasse, sentíamos vergonha. Ficamos dez dias em um hotel. Saíamos para passear juntas e fazíamos tudo aquilo que não podíamos fazer na prisão. Bem, na rua ficávamos de olho porque em Ceuta tem muita gente que é de Tetuão e que poderia conhecer a Naima. Foi muito bonito, foi como ter uma relação de namoro normal. Quando estava com Naima, me sentia feliz, ela era carinhosa, atenta e protetora comigo. Mas logo chegou a hora de ir embora... deixar Naima lá partiu meu coração (Rita).

$\mathrm{O}$ afeto trocado entre elas nesse reencontro foi, pouco a pouco, penetrando as contenções que regiam dito contexto, dissolvendo a mesma fronteira que, muitas vezes, se apresentou implacavelmente intransponível. De volta à distância, a dor da ausência permite que Rita sonhe um futuro no qual, quem sabe algum dia, Naima cruze definitivamente a fronteira, e elas voltem a morar juntas, desta vez no bairro de Torre-romeu.

Não cabe dúvida de que a relação entre Rita e Naima segue em aberto e, portanto, afetando os processos de (des)fronteirização nos quais transitam. Se bem a fronteira se constitui por meio de movimentos dolorosos e violentos, a história de amor transnacional entre Rita e Naima gera um projeto de transformação, quer dizer, um sonho de reencontro saturado de alterações radicais nas dinâmicas de gestão da borda hispanomarroquina. Em sintonia com as teorizações de Stathis Gourgouris (1996 apud KIVKOVIK, 2006) a respeito das nações como uma forma de sonho e, especificamente, a capacidade do caráter fundamentalmente ininteligível dos sonhos para compreender a complexidade das nações, apontamos para a conveniência da emergência dos sonhos, vistos como máquinas de geração de significado, para a tradução da ambiguidade contida no entendimento da fronteira hispano-marroquina. Dito limite seria produzido por movimentos de ação e retração, processos de se fazer e desfazer, enredamentos na aparência ora rígida, ora porosa, múltiplas formações discursivas, imaginários coletivos e pensamentos sonhados.

Cavar pelas rotas das experiências oníricas de Rita supõe, além de uma possibilidade epistemológica válida para a concepção das formações de fronteira, igualmente um maior entendimento sobre o papel que joga o conteúdo dos sonhos como meio de expressão dos acontecimentos. Por serem superfícies arenosas comprometidas na criação e transformação da própria vivência, os processos figurativos integrados nas vicissitudes dos sonhos e no potencial imagético dos desejos tornam-se manifestação de certos predicados em devir da vida cotidiana. A linguagem multiforme dos sonhos de Rita cria narrativas que derramam um profundo conteúdo emocional sobre os trânsitos pela fronteira. 
Ao contornar o que poderíamos chamar de confins da existência, nos deparamos com as profundezas do subsolo solitário onde Rita se localiza. Em deslocamento, procuramos pensar como a elaboração imaginária do que Rita sonha fazer ou se tornar oferece um tratamento de modelagem ao caráter complexo, turbulento e inverossímil do Estadonação, suas margens e possíveis experimentações nele circunscritas. A consistência dos seus sonhos auxilia uma situação de dor insustentável e compõe uma posição existencial capaz de forjar a ponte intersticial entre o bairro de Torre-romeu, onde ela se encontra, e a casa de Naima, em Tetuão.

A potência dos sonhos como experiência vital delineia a produção da fronteira, garantindo outras possibilidades substanciais de representála. A fantasia criadora de um futuro feliz ao lado de Naima age como motor instigador de devires na construção dessa linha divisória. Os vislumbres de amor que aparecem nesse sonho de viverem juntas em um lugar afastado das violentas forças carcerárias operam como encarnações efetivas que enredam suas vidas com processos de fazer e desfazer zonas compartilhadas. É porque o sonho manifesta, interpreta e significa a fronteira, que ele atua como uma máquina produtora de versões contingentes e especulativas sobre sua existência. Nesta cartografia retorcida, poderíamos entender e descrever a borda hispanomarroquina como uma espécie de sonho em devir, ou diríamos, um devir-fronteira que transita entre o sonho e a vigília, e que se conjuga na dobra desses modos de habitar territórios e caminhadas.

\section{NOTAS}

1. O motivo da condenação e o caminho percorrido desde o momento da detenção até o encarceramento foram descritos de forma detalhada no artigo "Entre trânsitos e cárceres: os processos de (des)fazer a fronteira hispanomarroquina numa experiência prisional no Centro Penitenciário de Tetuão", de Montserrat Valle Prada (2019). Disponível em:

$<$ http://www.periodicos.ufc.br/revcienso/article/view/31756>. Acesso em: 08 set. 2020.

2. Jasbir Puar (2017) desenvolve o termo homonacionalismo para descrever o processo pelo qual a inclusão e a celebração da diversidade sexual passam a ocupar um papel central na elaboração de novas fantasias nacionalistas. $\mathrm{Na}$ Europa, desponta com força uma retórica islamofóbica dos discursos neoliberais sobre a sexualidade, juntamente a "marcos normalizadores dos direitos humanos de gays e lésbicas, que produzem países abertos à homossexualidade e países que a repudiam" (PUAR, 2017, p. 23).

3. Tratado que suprime os controles fronteiriços entre 30 países europeus, permitindo a livre circulação da sua população pelo denominado "espaço de Schengen". 


\section{REFERÊNCIAS}

BRAH, Avtar. Cartografias de la diáspora: Identidades en cuestión. Madrid: Traficantes de Sueños, 2011.

BUMACHAR, Bruna. Nem dentro, nem fora: A experiência prisional de estrangeiras em São Paulo. 2016. Tese (Doutorado em Antropologia Social) - Instituto de Filosofia e Ciências Humanas, Universidade Estadual de Campinas, 2016.

CARSTEN, Janet. After Kinship. Cambridge: The Press Syndicate of the University of Cambridge, 2004.

DAVIS, Angela; DENT, Gina. A prisão como fronteira: uma conversa sobre gênero, globalização e punição. Estudos Feministas, Florianópolis, v. 11, n. 2, p. 523-531, jul./dez. 2003.

FOUCAULT, Michel. Vigiar e punir: Nascimento da prisão. Petrópolis: Vozes, 2012.

KIVKOVIK, Marko. Sueños dentro-fuera: algunos usos del sueño en la teoría social y la investigación etnográfica. Revista de Antropología Social, Madrid, v. 15, p. 139-171, 2006.

MALLART, Fábio. Gestão neuroquímica: pílulas e injetáveis na prisão. In: MALLART, Fábio; GÓDOI, Rafael (Orgs.). BR 111: A rota das prisões brasileiras. São Paulo: Editora Veneta/Le Monde Diplomatique Brasil, 2017. p. 127-137.

PADOVANI, Natália Corazza. Sobre casos e casamentos: Afetos e "amores" através de penitenciárias femininas de São Paulo e Barcelona. 2015. 368 f. Tese (Doutorado em Antropologia Social) - Instituto de Filosofia e Ciências Humanas, Universidade Estadual de Campinas, 2015.

PAZ, Sabrina Rosa. "A Caravana do Amor": Um estudo sobre reciprocidades, afetos e sexualidade em um estabelecimento prisional que comporta homens e mulheres em seu interior, Rio Grande. 2009. 128 f. Dissertação (Mestrado em Ciências Sociais) - Instituto de Sociologia e Política, Universidade Federal de Pelotas, 2009.

PRADA, Montserrat Valle. Entre trânsitos e cárceres: os processos de (des)fazer a fronteira hispano-marroquina numa experiência prisional no Centro Penitenciário de Tetuão. Revista de Ciências Sociais, Fortaleza, v. 49, n. 3, p. 175-200, nov. 2018/fev. 2019.

PUAR, Jasbir. Ensamblajes terroristas: El homonacionalismo en tiempos queer. Barcelona: Edicions Bellaterra, 2017. 